\title{
The effects of sucrose and maize oil on subsequent food intake and mood
}

\author{
Marie Reid ${ }^{1 *}$ and Richard Hammersley ${ }^{2}$ \\ ${ }^{1}$ Medical Education Unit, Clinical Sciences Building, St James's Hospital, University of Leeds, \\ Leeds LS9 7TF, UK \\ ${ }^{2}$ Department of Sociological Studies, University of Sheffield, Sheffield S10 2FL, UK
}

(Received 23 June 1998 - Revised 13 May 1999 - Accepted 11 June 1999)

\begin{abstract}
The effects of sucrose and oil preloads were explicitly compared in a single-blind controlled trial using a between-subjects design. Eighty adult subjects (forty-three male, thirty-seven female) aged 18-50 years received at 11.00 hours one of four yoghurt preloads. All were $80 \mathrm{~g}$ low-fat, unsweetened yoghurt (188 kJ), containing additionally (1) saccharin (control, $23 \mathrm{~kJ}$ ), or (2) $40 \mathrm{~g}$ sucrose $(859 \mathrm{~kJ})$, (3) $40 \mathrm{~g}$ maize oil $(1569 \mathrm{~kJ})$, (4) $20 \mathrm{~g}$ sucrose, $20 \mathrm{~g}$ maize oil $(1213 \mathrm{~kJ})$. Subjects were normal eaters and of normal weight (male mean weight: 68.8 (SD 3.2) kg, BMI 21.8 (SD 1.6$) \mathrm{kg} / \mathrm{m}^{2}$; female mean weight: 53.7 (SD 5.1) kg, BMI 20.4 (SD 1.2) kg/m²). Food intake was measured with a food diary and mood with ten single Likert scales. ANOVA was conducted using preload type (saccharin, sucrose, oil, sucrose + oil), sex (male, female) and early $v$. late breakfast times as factors. Mood was analysed using the same design, with time of rating (immediate, $60 \mathrm{~min}, 120 \mathrm{~min}$ ) as an additional factor. Men ate more after the saccharin preload than after the other preloads, but did not vary the time of their next solid food. Women increased the intermeal interval only after the oil preload, which also had the highest energy content value, but did not vary the energy content of their next solid food. The saccharin preload decreased rated tiredness at $2 \mathrm{~h}$ compared with the sucrose preload, possibly due to its lower energy content. The preloads containing sucrose or sucrose + oil increased calmness between 1 and $2 \mathrm{~h}$ afterwards, compared with the saccharin preload. It is concluded that both sucrose and oil increase the intermeal interval in men, but that women are less sensitive to preloading. The mood effects suggest that tiredness after carbohydrate at $2 \mathrm{~h}$ may in part be a decrease in rated energy compared with the increased rated energy found after a preload with low energy content. Carbohydrate may genuinely increase calmness. These effects apply to non-restrained eaters of normal weight.
\end{abstract}

Food intake: Mood: Intermeal interval: Preloads

The typical British diet is high in fat and refined carbohydrates, relatively low in fibre, complex carbohydrates, fruit and vegetables. A high-fat diet is implicated in the development of CHD, some cancers, stroke, obesity and gastrointestinal disorders (Seeley et al. 1985). There are several barriers to reducing fat intake, including the following ingestive phenomena. First, high-fat food can be extremely palatable, particularly when it is mixed with sugars (Rolls, 1995). Lower-fat alternatives may be less palatable. Palatability will not be examined in the present study. Second, the rate of digestion tends to slow down as fat content increases, which may affect the onset and duration of satiety (Rolls, 1995). Lower-fat alternatives may be digested more rapidly and hunger may return sooner. It can be difficult experimentally to separate any specific satiating effects of fats from the effects of their energy density; high-fat foods tend also to be energy dense. Third, as will be reviewed, fat and sugars may both, alone or in combination, affect subjective mood.

Behavioural change after ingestion of specific macronutrients has been well documented in normal human subjects. For example, many studies have compared the effects of protein and fat, as well as protein and carbohydrate, on satiety (e.g. Geliebter, 1979; Stockley et al. 1984; de Castro, 1987; Rolls et al. 1988; Teff et al. 1989; Vanderwater \& Vickers, 1996; Reid \& Hetherington, 1997). There have also been studies directly comparing the effects of carbohydrate and fat on appetite (e.g. Rolls et al. 1994; Hulshof et al. 1995; Rolls, 1995; Rolls \& Hammer, 1995; WesterterpPlantenga et al. 1997). Generally, for isoenergetic loads protein is more satiating than either fat or carbohydrate (Booth et al. 1970; Hill \& Blundell, 1986; Spring et al.

*Corresponding author: Dr Marie Reid, fax +44 (0)113 206 4064, email M.C.Reid@Leeds.ac.uk 
1986; Teff et al. 1989; French et al. 1992). Fat may be less satiating than carbohydrate, but this effect may be restricted to the obese and restrained eaters (Rolls, 1995). It has also been suggested that specific nutrients have a direct relationship with mood. Decreased arousal and increased sleepiness have been frequently reported after carbohydrate-rich foods (Thayer, 1967; Lieberman et al. 1986a; Spring et al. 1986; Pivonka \& Grunewald, 1990). Several studies have also reported that fat reduces arousal (Lloyd et al. 1994, 1996; Wells et al. 1995; Wells \& Read, 1996, 1997). However, although many common foods are mixtures of fat and refined carbohydrate relatively few studies have explicitly compared the effects of carbohydrate and fat on both appetite control and mood (e.g. Lloyd et al. 1994, 1996; Wells et al. 1995). Even fewer studies have conducted a full comparison of a preload high in carbohydrate or fat with fasting or a placebo food. When comparing the effects of different macronutrients on behaviour, a problem arises in choosing a comparator, for there is no absolute baseline for mood or appetite and not eating, or fasting, has effects on both and so cannot be used as a 'no treatment' comparison. Furthermore, it is well known that virtually any intervention, even complete placebo, is liable to make people feel different (see Poulton, 1989), which intensifies the problem when subjective state is being assessed, as one cannot assume that changes from baseline are entirely a specific product of the specific intervention.

While differential effects of different macronutrients on mood have been reported, these tend to be small and a consistent pattern has not been found across different studies (Reid \& Hammersley, 1995, 1998; Rogers, 1995). Before accepting the effects of certain nutrients on appetite and mood, it is perhaps necessary to separate experimentally the following psychological effects from physiological effects of nutrients: (1) effects of the act of eating, particularly of eating nutrients other than carbohydrate; (2) effects of knowledge and expectations about what one is eating, and (3) effects of time of day, including the post-lunch circadian dip. It is also necessary to consider (4) sex differences, as men eat more than women (and hence may be less sensitive to a given preload intervention) and may also eat differently.

Regarding (1), as previously mentioned, there have been relatively few studies which compare the effects of carbohydrate and fat on mood and appetite in the same study. Furthermore, as Drewnowski (1987) pointed out, some previous work on carbohydrate has used high-carbohydrate food with a substantial uncontrolled fat content. The study reported here explicitly compares the effects of fat and carbohydrate, alone and in combination.

Regarding (2), in an attempt to control psychological factors, our previous studies (Reid \& Hammersley, 1994, 1995, 1998) administered sucrose preloads using a betweensubjects, blind design, with saccharin placebos, and assessed eating and mood in everyday life, rather than in controlled laboratory conditions. Results showed that sucrose ingestion increased the intermeal interval at both 09.30 hours and 11.00 hours. Subjects who had ingested sucrose did not eat until about $2 \mathrm{~h}$ after the preload, whereas most subjects who had ingested placebo ate within the next $2 \mathrm{~h}$. The energy content of meals was unaffected. It may be that sucrose has different satiating effects when ingested with fat.
Additionally, with regard to (3), previous studies that have reported significant effects of carbohydrates on mood have generally been conducted at about lunchtime (Spring et al. 1986; Smith \& Leekam, 1988; Craig \& Richardson, 1989); it is, however, likely that effects on mood vary with time of day (Craig, 1986) and previous diet. It may be that because more people habitually consume lunch than breakfast, effects of a controlled meal are more marked at lunchtime. This may in part be attributable to endogenous processes (Craig, 1986) rather than to the nutrient per se, as well as to the extent of fasting. It is possible, for example, that the effects of carbohydrate (or fat) on mood interact with the circadian post-lunch dip (Smith \& Leekam, 1988). Perhaps the effects of lunch are most marked at the time when the dip would be expected, but do not occur consistently over time. As well as comparing fat and carbohydrate, the study reported here gave preloads at 11.00 hours, that is, between meals rather than at breakfast or lunchtime.

Finally (4), regarding sex differences, in two previous studies (Reid \& Hammersley, 1994, 1995) we found that although a sucrose preload did not in itself affect the energy content or carbohydrate content of the next meal, men and women differed in their carbohydrate and energy intakes. Women were more likely to select foods that were lower in energy and carbohydrate content than men, irrespective of their body weight and whether they had received sucrose or not. In the earlier study (Reid \& Hammersley, 1994) men tended to eat and drink early to make up for having missed breakfast due to participating in the experiment. Such sex differences may be attributable to both physiological factors and psychological differences between men and women.

Another issue considered for the current study is how mood should be measured. Available measures of mood tend to be multidimensional and most studies have used more than one measure in an attempt to be comprehensive. The wide range of measures used complicates data analysis and increases the chances of falsely rejecting the null hypothesis. Another practical problem that we have found in previous studies (Reid \& Hammersley, 1994, 1995, 1998) is that subjects experience considerable test fatigue if asked to rate multiple items repeatedly over a period of hours. Furthermore, it has never been demonstrated that the mood ratings most widely used in nutrition research (McNair et al. 1971; Bond \& Lader, 1974; Herbert et al. 1976; Thayer, 1978, 1986, 1987; Thayer et al. 1994) are valid when used repeatedly over a period of hours, rather than over $24 \mathrm{~h}$ or more which is what they were primarily designed for. Hammersley et al. (1993) have shown that using nine Likert items is a valid method of measuring mood when used repeatedly over brief time periods and this approach was repeated here.

The aim of the present study was to compare the effects of fat and carbohydrate on eating behaviour and mood after preloads given at 11.00 hours, using a design and method aimed at separating the physiological effects of digesting fat and carbohydrate from psychological effects brought about by confounding factors including the act of eating, expectations about the effects of different foods, the time of day and test fatigue. 
Table 1. Characteristics of the subjects used in the present study

(Mean values, standard deviations and ranges)

\begin{tabular}{|c|c|c|c|c|c|c|}
\hline \multirow[b]{2}{*}{ Measure } & \multicolumn{3}{|c|}{ Male $(n 43)$} & \multicolumn{3}{|c|}{ Female ( $n$ 37) } \\
\hline & Mean & SD & Range & Mean & SD & Range \\
\hline $\mathrm{BMI}\left(\mathrm{kg} / \mathrm{m}^{2}\right)$ & $21 \cdot 8$ & 1.6 & $17 \cdot 6-25 \cdot 1$ & $20 \cdot 4$ & 1.2 & $18 \cdot 2-24 \cdot 0$ \\
\hline Weight (kg) & 68.8 & $3 \cdot 2$ & $59.0-74.9$ & 53.7 & $5 \cdot \overline{1}$ & $45.4-69.9$ \\
\hline Height $(\mathrm{m})$ & 1.777 & 0.066 & $1.676-1.905$ & 1.622 & 0.069 & $1.448-1.854$ \\
\hline Age (years) & $30 \cdot 6$ & 4.6 & $22-42$ & $30 \cdot 3$ & $5 \cdot 2$ & $24-46$ \\
\hline Daily energy intake $(\mathrm{kJ})$ & 8364 & 2586 & $3523-14518$ & $6393^{* *}$ & 1992 & $2335-10192$ \\
\hline Daily fat intake (g) & 82 & 35 & $12-171$ & $63^{\star *}$ & 28 & $9-124$ \\
\hline Daily carbohydrate intake (g) & 238 & 82 & $95-436$ & $178^{* *}$ & 64 & $51-289$ \\
\hline
\end{tabular}

Mean values were significantly different from those for men: ${ }^{* *} P<0.01$.

\section{Methods}

\section{Design}

In a randomized between-subjects design subjects were given blind at 11.00 hours one of four yoghurt preloads, comprising a control preload with added saccharin only, a high-carbohydrate preload with added sucrose, a high-fat preload with added maize oil, or a mixed preload with added sucrose and maize oil. Full details of the preloads are given later. Mood was monitored for $2 \mathrm{~h}$ afterwards and food consumption was recorded in hourly diaries until sleep that night.

\section{Subjects}

Eighty subjects (forty-three males, thirty-seven females) aged 18-50 years took part in the study and were recruited from places of employment in Dundee and Glasgow. Table 1 shows subject characteristics. Volunteers were requested to complete the eating disorder inventory (Garner, 1990), a standardized self-report measure which consists of eight subscales related to specific behavioural and psychological dimensions important in anorexia nervosa and bulimia. Whilst no subjects were overweight, some subjects were slightly underweight (see Table 1), however, only subjects scaling within $20 \%$ of eating disorder inventory weight norms for their age, sex and height were included in the study. All subjects were requested to have whatever breakfast they would normally consume. Subjects were informed that they were taking part in a food study that was investigating the effects of certain food properties on human behaviour. They were requested to eat as normal before and after the test food on the experimental day. Diaries showed no evidence of unusual eating patterns either before or after the test food. Subjects were informed in advance that they would receive a yoghurt and that to control sensory and olfactory cues anaesthesia and nose clips would be employed. Subjects were randomly assigned to treatment conditions.

\section{Preloads}

In our previous research on sucrose (Reid \& Hammersley, $1994,1995,1998)$, we used liquid preloads. Here, in order to emulsify the oil, low-fat, unsweetened yoghurt was used as the medium instead. The yoghurt was kept refrigerated and
$80 \mathrm{~g}$ was then weighed into a small plastic container, to which was added one of the following: (1) saccharin only (4.34 g), or (2) $40 \mathrm{~g}$ sucrose (giving a total of $90 \%$ energy as carbohydrate), or (3) $40 \mathrm{~g}$ maize oil (giving a total of $90 \%$ energy as fat), or (4) $20 \mathrm{~g}$ sucrose and $20 \mathrm{~g}$ maize oil (giving $37 \%$ energy as carbohydrate, $59 \%$ energy as fat). Table 2 shows the nutrient content of the preloads, which contained the same weight of sucrose or oil but were not completely isoenergetic. Preloads were mixed thoroughly. Pilot work (Reid, 1995) showed that all preloads were palatable and did not produce symptoms such as nausea, indigestion or diarrhoea. Pilot research (Reid, 1995) also indicated that residual sensory differences between the preloads were not detectable after suppressing olfaction with nose clips, and taste with anaesthesia of the mouth. This method was modelled after Geliebter (1979).

\section{Visual analogue scales}

Ten $80 \mathrm{~mm}$ long visual analogue scales with an adjective at each end were used to assess subjective mood state. The content validity of the adjectives was produced as follows: (a) Thayer's (1978) two dimensions of arousal: (1) tiredenergetic, (2) restless-relaxed; (b) hedonic tone: (3) happysad. This is agreed to be the second main dimension of mood after arousal (Thayer et al. 1994), which may or may not overlap with Thayer's (1978) two dimensions. (c) Physical state: (4) hungry-full, (5) thirsty-not thirsty, (6) intoxicatedsober, (7) ill-well. These measures are obviously salient to studies of ingestion and appetite. (d) Other emotions: (8) angry-calm, (9) anxious-composed, (10) disgusted-satisfied. These measures describe emotions which can be discriminated from facial expressions (see Frijda, 1986) and

Table 2. Nutrient content of yoghurt preloads containing saccharin, sucrose, maize oil or sucrose + maize oil

\begin{tabular}{lcccc}
\hline Preload ... & $\begin{array}{c}\text { Sucrose } \\
\text { maize oil }\end{array}$ & Sucrose & Maize oil & Saccharin \\
\hline Total energy (kJ) & 1213 & 858 & 1569 & 230 \\
Fat $(\mathrm{g})$ & 20.6 & 0.6 & 40.6 & 0.6 \\
CHO (g) & 26.0 & 46.0 & 6.0 & 6.0 \\
Fat (\% energy) & 58.8 & 2.4 & 89.6 & 9.0 \\
CHO (\% energy) & 36.8 & 89.8 & 6.4 & 44.4 \\
Protein (\% energy) & 5.3 & 7.8 & 4.0 & 46.6 \\
\hline
\end{tabular}

$\mathrm{CHO}$, carbohydrate. 
which are not included in the measures of arousal and hedonic tone. The merits of this instrument are that it is both brief and comprehensive in the sense of covering all major established dimensions of subjective state. It is assumed that if subjects feel a short-term change in mood, then they should be able to represent this change on a single visual analogue scale. It should be noted that this is different from when subjects are attempting to rate their mood over a longer time period, such as $24 \mathrm{~h}$.

\section{Procedure}

At the initial interview subjects' heights and weights were recorded. All volunteers then completed the eating disorder inventory (Garner, 1990) and the eating disorder inventory symptom checklist (Garner, 1990) which provides data on dieting, weight, exercise patterns and the frequency of disordered eating symptoms. No subject scored above the criteria for eating disorders. Each subject then rated their mood using the mood questionnaire described earlier. Subjects were issued a prospective hourly diary for $7 \mathrm{~d}$, and instructed to fast from breakfast to test on the experimental day. All subjects were given clear instructions and training (approximately $20 \mathrm{~min}$ ) on how to complete the diary by the experimenter, including the use of photographs of reference portion sizes, and were asked to record all food and liquid intake for the week before testing (after Bone, 1992). The diaries were used to monitor previous food intake and to provide baseline data that would permit a comparison of eating behaviour before and after the experiment. On the morning of the experiment, subjects' diaries were checked by the experimenter for adequate completion and any problems with data were clarified. Unweighed diaries are valid indices of nutrient intake (within 15\%) as long as clear adequate instructions about portion sizes and food names are given (Karvetti \& Knuts, 1992; De Castro, 1994; Geekie \& Raats, 1995). They have been successfully used previously for examining differences in intake (e.g. Reid \& Hammersley, 1994, 1995, 1998; Steptoe et al. 1998; Bellisle et al. 1999).

Subjects returned at 11.00 hours on a scheduled day, when they were randomly assigned to treatment conditions. In order to depress taste and texture perception subjects were asked to suck a benzocaine anaesthetic lozenge (Tyrozets, containing $1 \mathrm{mg}$ Tyrothricin and $5 \mathrm{mg}$ Benzocaine) for 3 min before consumption of the test food; this produced a mild anaesthesia of the mouth (after Millar et al. 1992). Pilot research (Reid, 1995) indicated that this effect occurs $1 \mathrm{~min}$ into the sucking process and lasts approximately 30 $50 \mathrm{~min}$. Subjects were also asked to wear nose clips whilst eating the yoghurt to eliminate its aroma. At the same time, they completed baseline visual analogue scales, which took approximately $2 \mathrm{~min}$. Subjects then received, blind, one of the four yoghurt preloads summarized in Table 2. Preloads systematically varied carbohydrate and fat content while approximately matching energy content and orosensory properties.

Subjects consumed the yoghurt in $10 \mathrm{~min}$. The visual analogue scales were administered again immediately after subjects had finished the yoghurt. They were asked to complete the scales 60 and $120 \mathrm{~min}$ after eating. They were also instructed to self-complete yet another food diary which was to be filled in over the next $24 \mathrm{~h}$, using $1 \mathrm{~h}$ time slots. Because the final $24 \mathrm{~h}$ diary was issued after 11.00 hours on the test day the first few hours of the diary (before 11.00 hours) were completed retrospectively. At $2 \mathrm{~d}$ later when subjects returned the results to the experimenter they were asked if they had experienced any nausea or other unpleasant symptoms such as diarrhoea or constipation after eating the yoghurt. No subject reported any such effect. Subjects were finally debriefed in writing about the purpose of the study.

Preliminary ANOVA comparing groups on baseline measures showed that there were no baseline differences in mood between groups, between sexes, or compared with mood ratings the previous week. Initial ANOVA including BMI as a covariate found no effects of BMI on eating behaviour or mood and this variable was not included in the analyses reported here. To control for individual differences, mood scores after the preload were expressed as deviations from baseline mood ratings.

\section{Measures}

From the $7 \mathrm{~d}$ diaries were extracted (1) mean breakfast time (being the first hour of the day when solid food was consumed); (2) mean lunch time (being the first hour after 11.00 hours when solid food was consumed).

From the $24 \mathrm{~h}$ diaries were extracted: (1) time of any solid food, to the nearest hour, before the yoghurt preload. This was referred to as breakfast; (2) energy content of any food consumed before testing, calculated assuming standard portion sizes from Davies \& Dickerson (1991) and including all foodstuff, solid and liquid (i.e. breakfast); (3) energy content of any beverages taken without solid food before testing (calculations mainly involved the energy content of milk and sugar consumed in tea or coffee); (4) time of next solid food after the preload, to the nearest hour. A meal was defined as all food and drink consumed within the first hour period following the preload during which solid food was consumed. It should also be noted that mean time of administration (11.00-11.15 hours) did not differ between groups; (5) energy content of next solid food, including all solid and liquid foodstuffs, consumed within the respective hour time slot; (6) energy content of any beverages taken without solid food after testing (again calculations mainly comprised the energy content of milk and sugar consumed in tea or coffee).

\section{Results \\ Eating behaviour}

Preliminary analysis found that different experimental groups had accidentally varied in their breakfast consumption due to individual differences in breakfast choices. It was therefore necessary to consider this as a factor in the analyses of subsequent eating behaviour, so subjects who had eaten breakfast were divided by a median split into 'early breakfasters', who had eaten it before 09.00 hours and 'late breakfasters' who had eaten between 09.00 and 11.00 hours, with 'non-breakfasters' as a third group. Time of the next solid food after the test yoghurt and the meal's energy content were examined with two ANOVA using preload 
(saccharin, sucrose, oil, sucrose + oil), sex (male or female), breakfast time (no breakfast, early, or late) as factors. This 'next solid food' is hereafter referred to as 'lunch', which comprised all food and drink ingested during the first hour when any solid food at all was eaten.

There was a marginal main effect of preload on time of lunch $(F[3,58] 2 \cdot 6, P=0.063)$ with no other effects. The energy content of lunch was affected by preload $(F[3,58]$ $4 \cdot 1, P<0.05)$, sex $(F[1,58] 14.9, P<0.05)$ and time of breakfast $(F[2,58] 3 \cdot 6, P<0 \cdot 05)$. There was also a significant preload $\times$ sex interaction $(F[3,58] 5 \cdot 1, P<0 \cdot 05)$. All the subjects who ate during the hour after preload (11.00 hours) were male, which probably explains the absence of a significant difference between preloads for male subjects. Fig. 1 shows these data. The trends are quite clear: subjects who received saccharin mostly ate between 12.00 and 13.00 hours and all before 14.00 hours. Most subjects who received one of the other preloads ate between 13.00 and 14.00 hours, some ate even later. A few men who received oil or oil + sucrose ate between 11.00 and 12.00 hours.

Because of the sex differences, post-hoc comparisons were made separately for men and women using one-way ANOVA with preload as the factor and Tukey-HSD tests. Among men, preload did not significantly affect lunch time, but those who received saccharin consumed significantly more energy at lunch than all other groups (Fig. 2). Among women, preload significantly affected lunch time: those who received the oil preload (also the highest in energy content) ate significantly later than those who received saccharin. However, there were no effects of preload on the energy content of lunch (Fig. 2). Nonetheless, there was
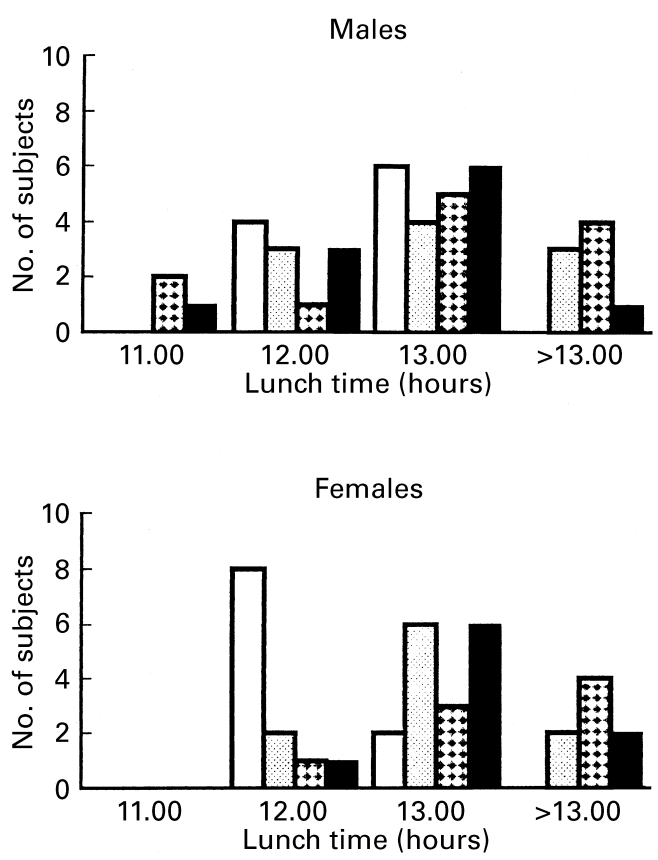

Fig. 1. Effects of different yoghurt-based preloads on the timing of lunch in male and female subjects. Preloads contained: ( $\square$ ), saccharin;

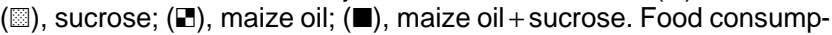
tion was recorded in an hourly diary and 'lunch' was defined as everything eaten and drunk in the first hour after the preload in which any solid food was consumed.

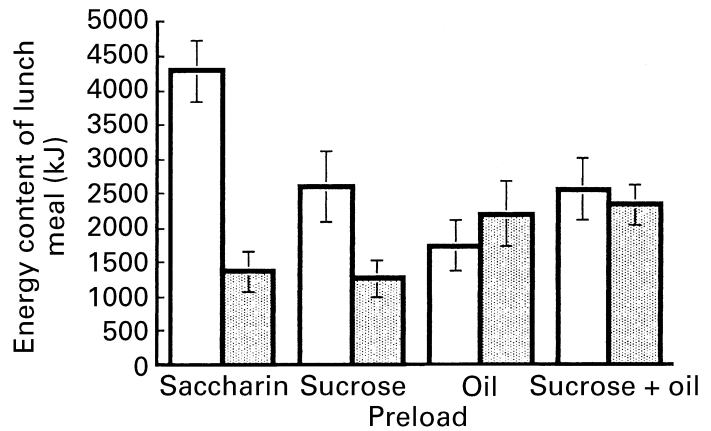

Fig. 2. Energy content of lunch meals eaten by male ( $\square$ ) and female (囼) subjects after yoghurt-based preloads containing saccharin, sucrose, maize oil or maize oil + sucrose. Values are means for twenty subjects, with their standard errors represented by vertical bars. Food consumption was recorded in an hourly diary and 'lunch' was defined as everything eaten and drunk in the first hour after the preload in which any solid food was consumed.

a non-significant trend for the women who received oil or oil + sucrose to eat more than those who received saccharin or sucrose only.

Because of these sex differences, one-way ANOVA were conducted comparing men and women on their total daily fat, carbohydrate and energy intakes, as well as on the ratios of fat and carbohydrate to total energy intake. Table 1 shows the differences between men and women. However, when fat and carbohydrate intakes were expressed as a proportion of daily energy intake, the sex differences disappeared. Thus, men ate more than women, but both ate the same proportions of fat and carbohydrate.

\section{Mood}

Between-group comparisons. Mood scales were analysed using repeated measures ANOVA with time of test (immediate, $60 \mathrm{~min}, 120 \mathrm{~min}$ ) as the repeated measure and preload as the independent variable. Separate analyses were conducted for each mood scale because no theory predicts that food should affect all mood scales consistently, but it is important to check that predicted mood effects on calmness or tiredness are not merely a function of some more general response bias, or confounded with other mood changes. Averaged or multivariate tests are reported depending on the significance of the Mauchly sphericity test (following West, 1991). Sex differences and the effects of breakfast timing were not examined because previous research suggests that a cell size of ten may be insufficiently powerful to detect mood changes (Reid \& Hammersley, 1995). Post-hoc comparisons were made separately comparing the four groups at each time of test (immediate, $60 \mathrm{~min}, 120 \mathrm{~min}$ ), using one-way ANOVA and Tukey tests.

Fig. 3 shows rated tiredness-energy. The only significant effect was a preload $\times$ time of test interaction $(F[6,152] 3 \cdot 1$, $P<0.05$ ). Compared with saccharin, by post-hoc Tukey tests, subjects receiving the sucrose-only preload felt more tired at $120 \mathrm{~min}$, but there were no other significant differences between groups, the oil and oil + sucrose groups being intermediate between the sucrose and saccharin groups. 


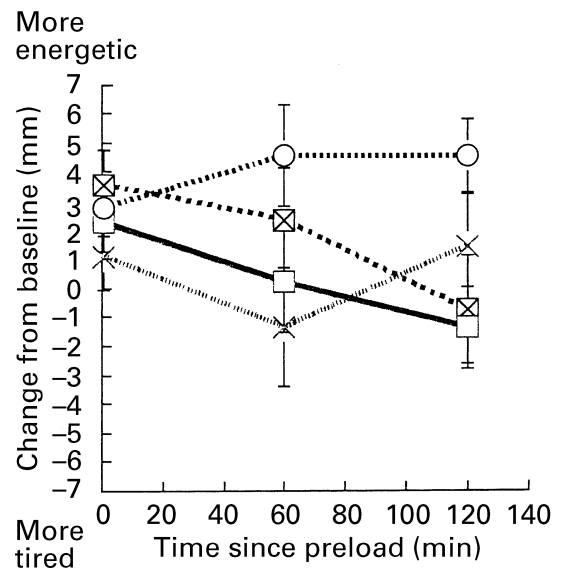

Fig. 3. Changes in rated energy-tiredness (on an $80 \mathrm{~mm}$ visual analogue scale) in subjects receiving yoghurt-based preloads contain-

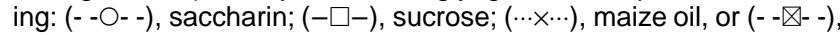
maize oil+sucrose. Values are means for twenty subjects with their standard errors represented by vertical bars.

Fig. 4 shows rated anger-calmness. One subject had missing data and was excluded from this analysis. There was a main effect of preload $(F[3,75] 5 \cdot 5, P<0.05)$ and a main effect of time of test $(F[2,74] 6 \cdot 0, P<0 \cdot 05)$, as well as a preload $\times$ time of test interaction $(F[6,146] 2 \cdot 6, P<0 \cdot 05)$. Compared with saccharin, by Tukey tests at 60 min subjects receiving sucrose preloads and oil + sucrose preloads both felt calmer. At $120 \mathrm{~min}$ only subjects receiving oil and sucrose together felt calmer than the saccharin group, with no other significant differences between groups.

There were no effects on the remaining eight mood scales. These included rated illness, confirming that none of the preloads made subjects nauseous.

Post-hoc within-group comparisons. The interpretation of Figs. 3 and 4 is not simple, because mood ratings tended to change over time, even after saccharin. Post-hoc paired $t$ tests (all $19 \mathrm{df}, P<0 \cdot 002$, corrected for multiple comparisons)

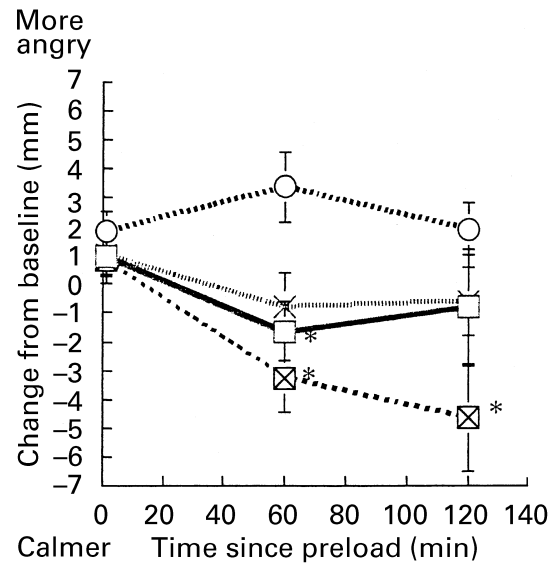

Fig. 4. Changes in rated calmness-anger (on an $80 \mathrm{~mm}$ visual analogue scale) in subjects receiving yoghurt-based preloads contain-

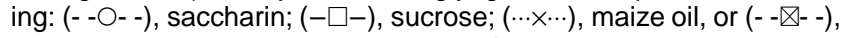
maize oil + sucrose. Values are means for twenty subjects with their standard errors represented by vertical bars. Mean values were significantly different from those for saccharin: ${ }^{*} P<0.05$. were conducted comparing raw tiredness and calmness ratings with the respective baseline scores, separately for each preload group. The saccharin group felt significantly more energetic at $120 \mathrm{~min}$ and marginally $(P=0.008)$ more energetic immediately after the preload. The sucrose group felt marginally $(P=0 \cdot 008)$ more energetic immediately after the preload but did not differ from baseline thereafter. Neither the oil group nor the oil + sucrose group differed significantly from baseline and rated calmness never differed from baseline.

\section{Discussion}

The present study found significant differences between preloads of differing nutrient composition on subsequent food intake and mood. The following specific effects were found. (1) Men ate less after any preload containing substantial energy content (sucrose, oil, oil + sucrose) compared with a saccharin preload, but their lunch times were unaffected. (2) Women who received oil ate later than those who received the other preloads (saccharin, sucrose, oil + sucrose). This could be a function of the oil preload having the largest energy content. (3) After saccharin rated energy increased relative to baseline $120 \mathrm{~min}$ later. This increase was sufficient to lead to significant differences in rated energy between saccharin and sucrose at that time. (4) Both sucrose and oil + sucrose preloads increased rated calmness relative to the oil preload, and this was not due to changes from baseline in the saccharin group.

In our previous work a liquid sucrose-containing preload increased the intermeal interval more than saccharin (Reid \& Hammersley, 1994, 1995, 1998). Here, using a less liquid preload, men did not increase the intermeal interval, but ate less after sucrose than after saccharin. However, they also ate less after oil and oil + sucrose. Women were less affected by preload content; they increased the intermeal interval significantly only after the oil preload, which also had the highest energy content, and did not significantly alter the content of their lunches. There was no evidence that either sucrose or oil triggered further eating; when they had effects they both satiated.

There was also evidence for effects of food on mood 1$2 \mathrm{~h}$ after eating. A low-energy saccharin preload increased rated feelings of energy both from baseline and compared with a high-energy sucrose preload. This effect did not reach significance for preloads containing oil; for these, rated energy did not significantly change from baseline. This pattern of findings suggests that apparent changes in tiredness after carbohydrate may be due in part to comparisons with semi-fasted conditions such as can occur before the administration of preloads, or by comparison across different preloads. If brain serotonin levels had increased tiredness, then rated energy should have decreased significantly from baseline in the sucrose condition.

Preloads containing sucrose also appeared to increase rated calmness, whether or not oil was also present. This effect was smaller than the effects on rated tiredness-energy and the experimental design was not powerful enough to detect specific post-hoc differences over time.

One limitation of these findings is that the time courses of the digestion and metabolism of oil and sucrose differ. If 
sucrose reduced the increased rated energy of semifasting at $2 \mathrm{~h}$, then an oil preload might have the same effect, but later, after this experiment terminated. Similar reasoning can be applied to calmness; both sucrose and oil + sucrose increased calmness at $1 \mathrm{~h}$, oil + sucrose continued to cause this effect at $2 \mathrm{~h}$. Would oil have had a similar effect later on? It is plausible that calmness and reduced rated energy are both functions of digestion in general, rather than of specific nutrients. However, the time course of digestion varies depending on the precise food mixture eaten.

The results are important in two respects. First, they show that both fat and carbohydrate satiate rather than enhance hunger in the short term, if cognitive cues are controlled. Second, the results show a relationship between carbohydrate ingestion and mood, although, as reported previously (Benton \& Owens, 1993) the effects were modest to the extent that the sample size used $(n 80)$ is probably close to the minimum where they would be detected.

Another limitation of the study is that the preloads used here were not isoenergetic and contained some protein, but the pattern of results found is not entirely explicable by the variations in energy content. These findings may not apply to the effects of pure carbohydrate, or pure fat, but effects of these pure nutrients have relatively little relevance for natural eating.

For future research, the issue of basal mood state seems particularly important. The largest mood effects have been reported in subjects with mood disorders (Wurtman, 1990), who feel calmer and more positive after carbohydrate-rich foods, although this improvement in mood may be absent under blind conditions (Toornvliet et al. 1997). In the present study, neither within- nor between-subjects comparisons alone would have given an accurate picture of the mood changes.

It is important that these results were obtained in normalweight subjects who were not restrained eaters. Although it has been proposed that carbohydrate and fat preloads have larger, easier to detect effects in special groups such as restrained eaters or dieters and some depressed people (Wurtman et al. 1981; Wurtman \& Wurtman, 1984; Lieberman et al. 1986) they ought also to affect normal people. At least, there is no physiologically plausible model that suggests otherwise. That normal people were affected here may have been due to the use of a simplified method of measuring mood, a relatively large sample and a betweensubjects design. It is sometimes suggested (e.g. Rogers, 1995) that within-subjects designs control for individual differences, but they can also introduce order effects that can confound experimental differences, such as the small effects of nutrients on mood.

These findings are consistent with the hypothesis that dietary constituents affect mood, but further research is required. Three issues are, first, the appropriate comparator for carbohydrate. No ideal comparator exists but, compared with baseline, a low-energy preload containing saccharin aroused, rather than sucrose decreasing arousal. Second, the effects of mixing fat with carbohydrate on digestion. Here, the fat-carbohydrate mixture apparently had slower effects on calmness than carbohydrate alone, perhaps reflecting a slower transfer of glucose into the blood. Third, in contrast to pure carbohydrate, Drenowski (1987) has questioned whether carbohydrate-fat mixtures can affect mood. Here, the fat-carbohydrate mixture did not reduce rated energy significantly less than carbohydrate alone. This raises the possibility that carbohydrates (or food in general) reduce arousal via a mechanism other than changes in serotonin levels, which is the mechanism most frequently proposed for the effects of carbohydrate. One possibility is that there are general effects of digestion on mood, which vary in their timing depending on the rate of digestion.

\section{Acknowledgements}

We thank Pauline Hubner for her assistance in coding the food diaries, and the Nuffield Foundation for funding this study.

\section{References}

Bellisle F, Dalix AM \& de Castro JM (1999) Eating patterns in French subjects studied by the "weekly food diary" method. Appetite 32, 46-52.

Benton D \& Owens D (1993) Is raised blood glucose associated with the relief of tension? Journal of Psychosomatic Research 37, 723-725.

Bond A \& Lader M (1974) The use of analogue scales in rating subjective feelings. British Journal of Medical Psychology 47, 211-218.

Bone A (1992) Methods for studying food consumption (specified time methods). In Promotion of Healthier Eating, pp. 169-188 [JR Kemm and D Booth, editors]. London: H.M. Stationery Office.

Booth DA, Chase A \& Campbell AT (1970) Relative effectiveness of protein in the late stages of appetite suppression in man. Physiology and Behavior 5, 1299-1302.

Craig A (1986) Acute effects of meals on perceptual and cognitive efficiency. Nutrition Reviews 44, Suppl., 163-171.

Craig A \& Richardson E (1989) Effects of experimental and habitual lunch size on performance, arousal, hunger, and mood. Internal Archives of Occupational and Environmental Health 61, 313-319.

Davies J \& Dickerson J (1991) Nutrient Content of Food Portions. Cambridge: Royal Society of Chemistry.

de Castro JM (1987) Macronutrient relationships with meal patterns and mood in the spontaneous feeding behavior of humans. Physiology and Behavior 39, 561-569.

de Castro JM (1994) Methodology, correlation analysis, and interpretation of diet diary records of the food and fluid intake of free-living humans. Appetite 23, 179-192.

Drewnowski A (1987) Changes in mood after carbohydrate consumption. American Journal of Clinical Nutrition 46, 703.

French JA, Wainwright CJ, Booth DA \& Hamilton J (1992) Effects of meat species and particle size on postprandial satiety. Proceedings of the Nutrition Society 51, 57A.

Frijda NH (1986) The Emotions. Cambridge: Cambridge University Press.

Garner DM (1990) Eating Disorder Inventory-2 (EDI2). Professional Manual. Odessa, FL: Psychological Assessment Resources.

Geekie MA \& Raats MM (1995) The development of a 7-day food and drink diary. Appetite 24, 282-283.

Geliebter A (1979) Effects of equicaloric loads of protein, fat and carbohydrate on food intake in the rat and man. Physiology and Behavior 22, 267-273. 
Hammersley RH, Finnigan F \& Millar K (1993) The structure of the expected and actual subjective effects of alcohol. Addiction Research 1, 207-222.

Herbert M, Johns MW \& Dore C (1976) Factor analysis of analogue scales measuring subjective feelings before and after sleep. British Journal of Medical Psychology 49, 373379.

Hill AJ \& Blundell JE (1986) Macronutrients and satiety: the effects of a high protein or high carbohydrate meal on subjective motivation to eat and food preferences. Nutrition and Behaviour 3, 133-144.

Hulshof T, De Graaf C \& Weststrate JA (1995) Short-term effects of high-fat and low-fat high-SPE croissants on appetite and energy-intake at 3 deprivation periods. Physiology and Behavior 57, 377-383.

Karvetti RL \& Knuts LR (1992) Validity of the estimated food diary - comparison of 2-day recorded and observed food and nutrient intakes. Journal of the American Dietetic Association 92, 580-584.

Lieberman HR, Spring BJ \& Garfield GS (1986) The behavioural effects of food constituents: strategies used in studies of amino acids, protein, carbohydrate and caffeine. Nutrition Reviews $\mathbf{4 4}$, Suppl., 61-69.

Lieberman HR, Wurtman J \& Chew B (1986) Changes in mood after carbohydrate consumption among obese individuals. American Journal of Clinical Nutrition 45, 772-778.

Lloyd HM, Green MW \& Rogers P (1994) Mood and cognitive performance effects of isocaloric lunches differing in fat and carbohydrate content. Physiology and Behavior 56, 51-57.

Lloyd HM, Rogers P, Hedderley DI \& Walker AF (1996) Acute effects on mood and cognitive performance of breakfasts differing in fat and carbohydrate content. Appetite 27, 151164.

McNair DM, Lorr M \& Droppleman LF (1971) Manual: Profile of Mood States. San Diego, CA: Educational and Industrial Testing Service.

Millar K, Hammersley RH \& Finnigan F (1992) Reduction of alcohol-induced performance impairment by prior ingestion of food. British Journal of Psychology 83, 261-278.

Pivonka EEA \& Grunewald KK (1990) Aspartame or sugar sweetened beverages' effects on mood in young women. Journal of the American Dietetic Association 90, 250-252.

Poulton EC (1989) Bias in Quantifying Judgements. London: Lawrence Erlbaum.

Reid M (1995) The effects of carbohydrates on mood and eating behaviour in the obese and non obese. PhD Thesis, University of Glasgow.

Reid M \& Hammersley RH (1994) The effects of sucrose on everyday eating in normal weight men and women. Appetite $\mathbf{2 2}$, 221-232.

Reid M \& Hammersley RH (1995) Effects of carbohydrate intake on subsequent food intake and mood state. Physiology and Behavior 58, 421-427.

Reid M \& Hammersley RH (1998) The effects of carbohydrates on hunger and mood in obese and non-obese women. Psychology, Health and Medicine 3, 299-313.

Reid M \& Hetherington M (1997) Relative effects of carbohydrates and protein on satiety - A review of methodology. Neuroscience and Biobehavioral Reviews 21, 295-308.

Rogers PJ (1995) Food, mood and appetite. Nutrition Research Reviews 8, 243-369.

Rolls BJ (1995) Carbohydrates, fats and satiety. American Journal of Clinical Nutrition 61, S960-S967.

Rolls BJ \& Hammer VA (1995) Fat, carbohydrate, and the regulation of energy-intake. American Journal of Clinical Nutrition 62, S1086-S1095.

Rolls BJ, Hetherington M \& Burley VJ (1988) The specificity of satiety: the influence of foods of different macronutrient content on the development of satiety. Physiology and Behavior 43, 145-153.

Rolls BJ, Kimharris S, Fischman MW, Foltin RW, Moran TH \& Stoner SA (1994) Satiety after preloads with different amounts of fat and carbohydrate - implications for obesity. American Journal of Clinical Nutrition 60, 476-487.

Seely S, Freed DLJ, Silverstone GA \& Rippere V (1985) Dietrelated Diseases. The Modern Epidemic. London: Croom Helm.

Smith AP \& Leekam S (1988) The influence of meal composition on post-lunch changes in performance efficiency and mood. Appetite 10, 195-203.

Spring B, Chiodo J, Harden M, Bourgeois M, Lutherer L, Harner D, Crowell S \& Swope G (1986) Effects of noon meals varying in nutrient composition on plasma amino acids, glucose, insulin and behaviour. Psychopharmacology Bulletin 22, 10261035.

Steptoe A, Lipsey Z \& Wardle J (1998) Stress, hassles and variations in alcohol consumption, food choice and physical exercise: a diary study. British Journal of Health Psychology $\mathbf{3}$, 51-63.

Stockley L, Jones FA \& Broadhurst AJ (1984) The effects of moderate protein or energy supplements on subsequent nutrient intake in man. Appetite 5, 209-219.

Teff KL, Young SN \& Blundell JE (1989) The effect of protein or carbohydrate breakfasts on subsequent plasma amino acid levels, satiety and nutrient selection in normal males. Pharmacology, Biochemistry and Behaviour 34, 829-837.

Thayer RE (1967) Measurement of activation through self-report. Psychological Reports 20, 663-678.

Thayer RE (1978) Factor analytic and reliability studies on the Activation-Deactivation Adjective Check List. Psychological Reports 42, 747-756.

Thayer RE (1986) Activation-Deactivation Adjective Check List: current overview and structural analysis. Psychological Reports 58, 607-614.

Thayer RE (1987) Energy, tiredness, and tension effects of a sugar snack versus moderate exercise. Journal of Personality and Social Psychology 52, 119-125.

Thayer RE, Newman R \& McClain TM (1994) Self regulation of mood: strategies for changing a bad mood, raising energy and reducing tension. Journal of Personality and Social Psychology 67, 910-925.

Toornvliet AC, Pijl H, Tuinenburg J, Wever BMED \& Pieters MSM (1997) Psychological and metabolic responses of carbohydrate craving obese patients to carbohydrate, fat and protein-rich meals. International Journal of Obesity 21, 860864.

Vandewater K \& Vickers Z (1996) Higher-protein foods produce greater sensory-specific satiety. Physiology and Behavior 59, 579-583.

Wells AS \& Read NW (1996) Influences of fat, energy, and time of day on mood and performance. Physiology and Behavior 59, 1069-1076.

Wells AS \& Read NW (1997) Influences of fat and carbohydrate on postprandial sleepiness, mood, and hormones. Physiology and Behavior 61, 679-686.

Wells AS, Read NW \& Craig A (1995) Influences of dietary and intraduodenal lipid on alertness, mood, and sustained concentration. British Journal of Nutrition 74, 115-123.

West R (1991) Computing for Psychologists: Statistical Analysis Using SPSS and MINITAB. London: Harwood.

Westerterp-Plantenga MS, Wijckmans-Duijsens NEG, VerboeketVande-Venne WPHG, De Graaf K, Weststrate JA \& Hof KHV (1997) Diet-induced thermogenesis and satiety in humans after full-fat and reduced-fat meals. Physiology and Behavior 61, 343-349. 
Wurtman JJ (1990) Relationship between carbohydrate intake and disorders of mood. Drugs 39, Suppl. 3, 49-52.

Wurtman JJ, Wurtman RJ, Growdon JH, Henry P, Lipscomb A \& Zeisel SH (1981) Carbohydrate craving in obese people: suppression by treatments affecting serotoninergic transmission. International Journal of Eating Disorders 1, 2-15.
Wurtman RJ \& Wurtman JJ (1984) Impaired control of appetite for carbohydrate in some patients with eating disorders: its treatment with pharmacologic agents. In Anorexia Nervosa [D Ploog and K Pirke, editors]. New York, NY: Springer Verlag. 